\title{
A CBR-based Decision Support System Framework for Construction Supply Chain Risk Management
}

\author{
Vinit Kumar and N. Viswanadham
}

\begin{abstract}
Risk Management is an essential process of construction project planning. When a risk event occurs during project execution, the required actions are taken by project managers using their own experience and knowledge. While knowledge and experience gained in past projects is very useful in identifying and managing risks in a new project, such information resides primarily in Project Managers' minds and is seldom documented in a reusable form of information. A decision support system with a case-base of previously taken actions and a record of previous risk management plans can assist managers in risk management of construction supply chains in a new project. This paper suggests the framework of a Decision Support System adopting Case-Based Reasoning approach; which can support decision makers in preventive as well as interceptive construction supply chain risk management.
\end{abstract}

\section{INTRODUCTION}

A construction project supply chain may contain hundreds of firms, contractors; subcontractors; material and equipment suppliers; engineering and design firms; and consulting firms etc. (see [14] and [17]). It remains highly fragmented and involves many small and medium size suppliers and subcontractors (see [4] and [5]). Many times materials have to be imported and supply chain becomes global and more difficult to manage. Also construction projects need a high level of coordination among various stakeholders, who have conflicting interests (see [18]). Fig. 1 illustrates a typical channel for the supply chain of an imported material. A construction supply chain may consist of hundreds of such channels (for various materials and services) and involve risks at various nodes.

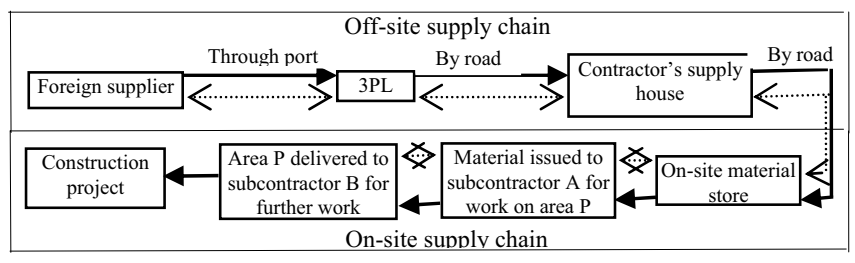

$\longrightarrow$ Material flow $\quad \cdots . . . .>$ Information flow

Fig. 1. A typical channel for material procurement

Vinit Kumar works as a researcher with Centre for Global Logistics and Manufacturing Strategies, Indian School of Business, Hyderabad, India (email: vinitkmishra@gmail.com)

N. Viswanadham is the Professor and Executive Director, Centre for Global Logistics and Manufacturing Strategies, Indian School of Business, Hyderabad, India (e-mail: N_viswanadham@isb.edu).
While risk management is a critical activity in construction project management, existing industry practices involve tools like risk registers, risk management spreadsheets, brain storming sessions etc. As a result many risks remain unidentified, and proper risk management becomes impossible (see [20] and [13]). Due to short-term project mentality of construction firms and return on investment issues, construction firms are averse of using Decision Support Systems for risk management.

Many industry people attribute the short-term mentality to the fact that each project is different. While each project is different in a general sense, structure of supply chain, many processes involved in construction projects, and materials remain common in different projects. As an example, every building construction will constitute processes like site preparation, masonry work, tiling etc. and materials like bricks, cement, sand etc. These similarity relations of various construction projects, motivate us to present the framework for a CBR-based Decision Support System (DSS) which can be used for risk management of construction supply chains in multiple projects.

After a construction firm signs the contract to deliver a project, the problem of handling supply chain risk due to unpredictable events is twofold, and has to be tackled at various strategic and operational levels. The first problem is of preventive risk management, in which the contractor has to find out various mechanisms in order to make the supply chain robust and risk resilient. The whole process involves identification of risk events with their sources, prioritizing risks, and devising ways in which probability of occurrence of such events can be minimized. The second problem is of interceptive risk management, where the contractor has to take a decision on the best action that should be taken subsequent to a risk event in order to contain the loss.

In section III onwards, we describe how a CBR-DSS, which can be used to handle preventive as well as interceptive risk management, can be built. Risk analysis tools along with the theory of CBR systems are used to present the framework.

\section{LITERATURE REVIEW}

Many authors have expressed their concerns about existing supply chain risk management practices in construction industries. Among them are, [13], who shows a few cases of improper risk prediction and importance of supply chain risk management in construction, and [10], 
who describe various causes of delays in construction projects in developing countries.

Ref. [11] provides a systematic way to quantify the uncertainty involved in construction schedules. [20] considers environmental risks in construction projects, where they discuss two case studies and suggest that the knowledge engineering tools can be used in managing environmental risks using the available knowledge in risk registers. [15] proposes a qualitative risk assessment model with a fuzzy logic approach. [2] uses Monte Carlo Simulations to analyze and evaluate construction project risks. [16] takes a Knowledge Engineering approach and present a qualitative risk analysis framework using object modeling for managing supply chain risks in construction projects. These efforts either provide suggestions or deal with risk analysis rather than providing a comprehensive solution for risk management.

Use of CBR systems is proposed to solve a wide range of experience-intensive problems. We suggest readers to refer to [8] which proposes the application of CBR systems in the risk analysis for electronic commerce, [19] which discusses the application of CBR-DSS for third party logistics evaluations, and [7] which proposes CRAS-CBR, a prototype CBR decision support model which supports the decision-making on the assessment of the level of control risk of the general accounting system in the manufacturing industry.

\section{PREPARATION FOR THE SYSTEM}

The whole process of CBR system is based on case representation. The case representation for preventive risk management should cover the important features of the project so that risks relevant to the current project can be covered in the retrieved cases and various alternatives to minimize the probability of risk events can be suggested. Also the system should be able to provide a measure of risk consequence associated with each risk event so that the prioritization of risks is possible. For interceptive risk management one has to make sure that system retrieves the most similar case/s of risk event and suitable mitigating strategies and alternatives are suggested. Designing an integrated CBR system for both the preventive and interceptive risk management of construction supply chain requires the clear understanding of various risks and critical project features which induce the risk events. In order to identify critical project features, it is important to know the nature of supply chain risks, the sources of risks and the consequences of risk events. Following subsections suggest tools to deal with them.

\section{A. Characteristics of construction supply chains}

The CBR system proposed here is based on the following characteristics of construction supply chains in the context of risk management.
1) A particular project type (road, airport, thermal power plant etc.) involves same materials, same processes, and a similar supply chain structure. Although technical specifications of components and equipments required can be different, suppliers and subcontractor firms may change but the inherent characteristics of supply chain remain the same.

2) For a construction project, a firm has to either procure materials/components/equipments or it has to procure services like design/engineering, electrical wiring etc. Issues in Supply Chain Risk Management of material and service supply chains are different and the partition of risk events in two categories of material procurement risk and service procurement risk gives an effective way of classification in case representation which would facilitate efficient and effective retrieval of cases in CBR system.

3) Some materials/services are highly prone to risk, while others are not. During risk management process one would like to focus on high risk-prone materials/services and leave the others. To serve an example for critical services, consider engineering projects like construction of oil platforms. Here engineering/design and site topographic survey are two highly critical services where a minor error may cause instability of platform and degenerate into huge losses. Material/service-specific supply chain risks are almost similar and remain independent of the project type. For example procurement of an industrial turbine involves almost similar supply chain risks, independent of whether it is used for hydro electric or thermal power plant.

A material/service is "critical", if the deviations associated with its cost, quality and delivery may result in a significant delay in construction, high cost over-runs, and unacceptable mismatch in specified project quality/scope.

Critical materials/services would change from project to project and a firm has to identify them for a project, based on the previous data of risk analysis. A description of such critical materials and services is shown in Table I and Table II respectively.

TABLE I

EXAMPLES AND DESCRIPTION OF CRITICAL COMPONENTS

\begin{tabular}{|l|l|}
\hline Description & Example \\
\hline $\begin{array}{l}\text { Component is critical to } \\
\text { project operation }\end{array}$ & A turbine in power plant \\
\hline $\begin{array}{l}\text { Continuous supply of } \\
\text { component is required }\end{array}$ & $\begin{array}{l}\text { Concrete in road building project, cement } \\
\text { in house building project }\end{array}$ \\
\hline $\begin{array}{l}\text { Component has to be } \\
\text { imported }\end{array}$ & $\begin{array}{l}\text { Any component which can not be procured } \\
\text { locally. }\end{array}$ \\
\hline Fewer suppliers are available & $\begin{array}{l}\text { A high-tech machinery which has few } \\
\text { suppliers }\end{array}$ \\
\hline $\begin{array}{l}\text { Susceptibility to damage is } \\
\text { high }\end{array}$ & Cement, glass materials etc. \\
\hline Substitution is not possible & $\begin{array}{l}\text { Technical component in which engineering } \\
\text { is involved. Ex. Turbine, pumps etc. }\end{array}$ \\
\hline A high price component & Baggage handling systems in airport \\
\hline
\end{tabular}




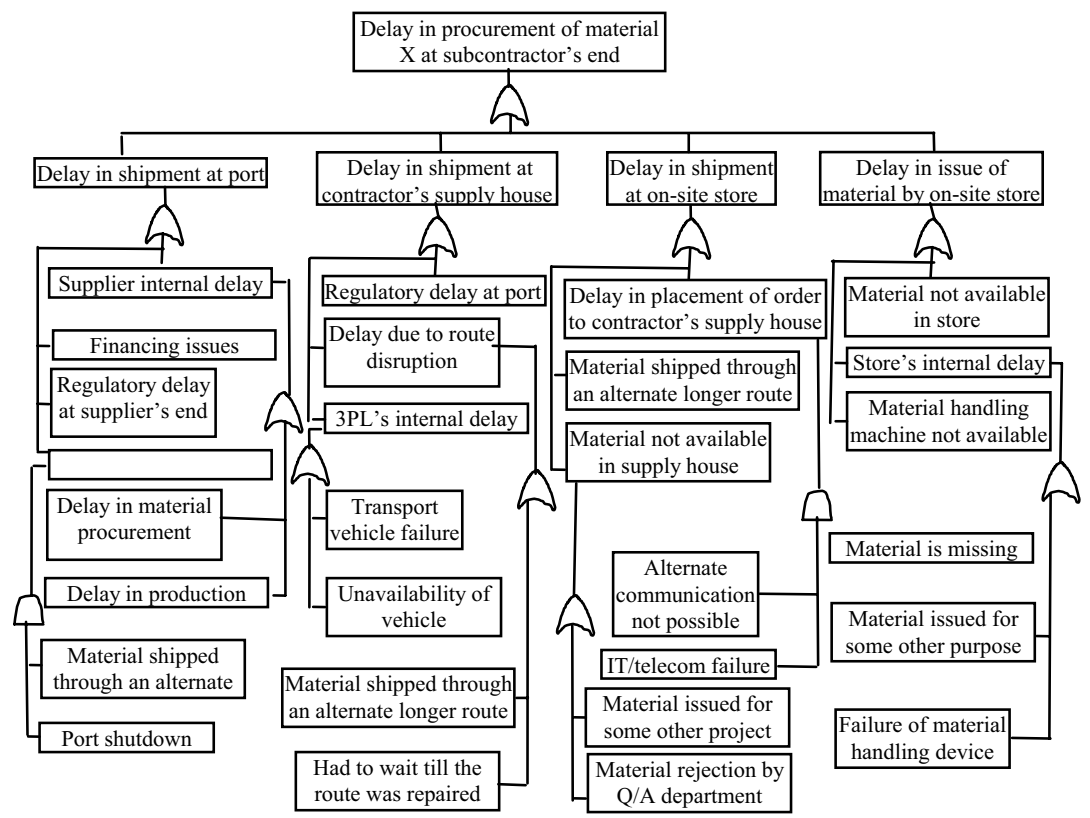

Fig. 2. Fault Tree Analysis of a failure event associated with a critical component $X$

TABLE II

EXAMPLES AND DESCRIPTION OF CRITICAL SERVICES

\begin{tabular}{|l|l|}
\hline Description & Example \\
\hline Service is critical to project operation & $\begin{array}{l}\text { Engineering \& design of } \\
\text { critical components in } \\
\text { Engineering projects. }\end{array}$ \\
\hline Long-term provision is required & Logistics services \\
\hline $\begin{array}{l}\text { Service requires highly technical } \\
\text { skills }\end{array}$ & Engineering consultancy \\
\hline Switching cost is high & Design services \\
\hline $\begin{array}{l}\text { Service has critical dependencies } \\
\text { (logical relationships) with other sub- } \\
\text { processes }\end{array}$ & Material procurement \\
\hline
\end{tabular}

\section{A. Identifying project features}

For the purpose of case representation it is important to identify the important project features which induce risk events and categorize them for efficient retrieval in CBR process. To identify these project features, one can perform a Fault Tree Analysis (FTA) for various risk events. FTA is used to identify basic causes of risk events and to find their probability of occurrence. Fig. 2 illustrates an example concerning the delay in procurement of a critical component (procurement channel is same as in fig. 1) at subcontractor's end.

FTA for various failure events suggests that some risk events are induced by the sources which are external to project features and type. Port shut-down and regulatory issues are two such examples. Other risk events are project feature-dependent and hence can be analyzed using the information regarding these features. Table III illustrates some of these project features. For example, poor connectivity of site to various suppliers induces risks of delays in procurement and cost over-run, natural disasters like flood may induce complete disruption in project execution, poor IT infrastructure and telecommunication may induce delayed information flow etc.

TABLE III

PROJECT FEATURE CATEGORIES

\begin{tabular}{|l|l|}
\hline Primary feature category & Secondary feature category \\
\hline Location features & Connectivity \\
\cline { 2 - 2 } & Topography \\
\cline { 2 - 2 } & Resource availability \\
\cline { 2 - 2 } Supplier/service provider & Susceptibility to natural disasters \\
\cline { 2 - 2 } features & Lead time \\
\cline { 2 - 2 } & Capacity constraints \\
\cline { 2 - 2 } & Quality of product \\
\cline { 2 - 2 } & Financial constraints \\
\cline { 2 - 2 } & Credit rating \\
\hline Support technology features & IT infrastructure \\
\cline { 2 - 2 } & Telecommunication \\
\cline { 2 - 2 } & Support equipments / machinery \\
\hline Project contract features & Time and quality specifications \\
\cline { 2 - 2 } & Penalty clauses \\
\cline { 2 - 2 } & $\begin{array}{l}\text { Susceptibility to project scope } \\
\text { change }\end{array}$ \\
\hline
\end{tabular}

The CBR system proposed here is based on the above mentioned characteristics of construction project supply chains and project features. As described in the subsequent sections, we use these characteristics so that an efficient retrieval of similar past cases is facilitated.

\section{SYSTEM ARCHITECTURE}

Main process of the proposed CBR system uses the widely accepted Aamodt-Plaza or $\mathrm{R}^{4}$ Model. Readers are encouraged to see [1] to find the details of this model. Four main processes of the model are Retrieve, Reuse, Revise, and Retain. The CBR process of the system is illustrated in fig. 3 .

The mentioned system process is facilitated by system 
architecture explained below. Various recommendations related to system architecture are made and a framework is presented rather than a solution of a specific case.

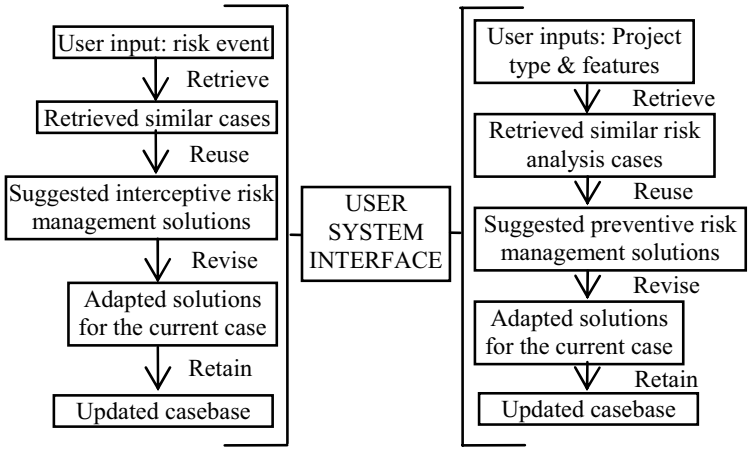

Fig. 3. CBR process for the integrated DSS: interceptive (left), preventive (right)

\section{A. Case representation}

We represent the case class as an 8 component-group as

$<T, F, C S, R, \operatorname{Pr}, C, I, \operatorname{Pr} e>$

where,

$\mathbf{T}$ is the type of project. The value of $\mathrm{T}$ can be airport, road, hydro power plant, railway etc.

$\mathbf{F}$ is an n-tuple describing features of the project. These features are same as mentioned in Table III.

CS is an n-tuple containing components or services to which the risk is associated. For example, the risk event "delay in procurement of a turbine due to port closure" will involve turbine as component and transportation of turbine as service.

$\mathbf{R}$ is a well defined $n$-tuple containing risk events such as "delay in component $\mathrm{X}$ due to cause $\mathrm{Y}$ "

$\mathrm{Pr}$ is the probability of occurrence of the risk event.

$\mathbf{C}$ is the consequence of the risk event in terms of expected loss. Wherever consequence can not be measured quantitatively, attribute values such as high/low quality deterioration or Delay of $\mathrm{x}$ days can be used.

I is an n-tuple of suggested interceptive risk mechanisms/strategies.

Pre is an n-tuple of possible preventive risk mechanisms/strategies to be used.

In case of preventive risk management, components $\mathbf{T}$ and F constitute the problem space and other components contain the solution space. User defines the problem by entering information regarding project type and features. Solution space consists of a list of components and services for the current project type, risk events associated with each of them, their probabilities, consequences of risk events and preventive risk management schemes. In case of interceptive risk management, where a risk event has occurred, problem space consists of the components $\mathbf{T}, \mathbf{F}, \mathbf{C S}$, and $\mathbf{R}$ and $\mathbf{I}$ (interceptive risk management strategies) form the solution space.

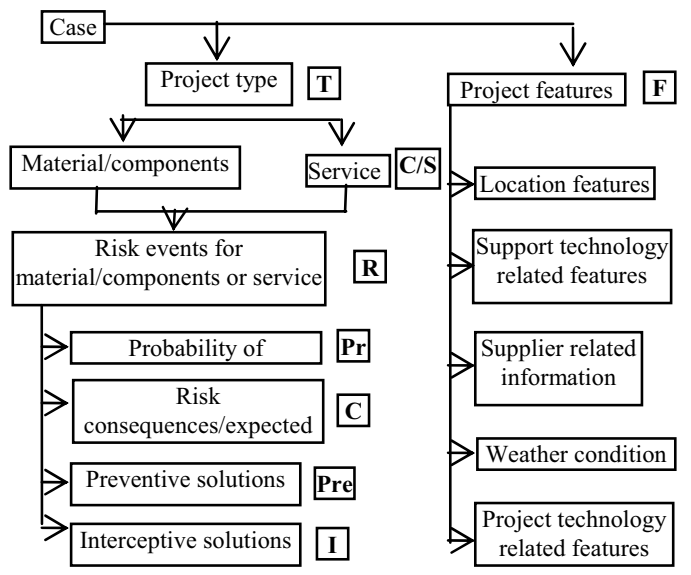

Fig. 4. Case hierarchy diagram for CBR-DSS

\section{B. Case indexing and Retrieve process}

Although the case base for preventive as well as interceptive risk management problems is common, retrieval functions would be different. Retrieval algorithm uses the appropriate retrieval function conditionally based on the user's selection of the problem type: interceptive/preventive. Indexing and similarity based matching processes for both the problems would be different as well.

Indexing allows the system to focus on the relevant features of the risk management problem, and hence make the system work effectively and efficiently. For preventive risk management problem, the project type is the only index, and other features of the problems are recommended to be matched based on similarity measures. In this case it would be assumed that the firm has dealt with the same type of project in the past. For interceptive risk management problem, the indexes can be assigned to project type, some of the project features, and components/services. In the integrated CBR system indexing would be conditional based on the user's section of preventive or interceptive risk management options.

The partial index-based matching is not sufficient as the case has several other features which could not be matched using indexes and also the exact matching is highly rare in most of the practical applications. Apart from indexing, the retrieval algorithm uses a qualitative and multi-attribute similarity based algorithm. Nearest-neighbor retrieval is the most commonly used technique in commercial applications (for details see [1]).

User should remember that for the preventive risk management problem the retrieval algorithm should retrieve the most important risk events so as to make preventive risk management cost effective. This can be accomplished by using a comparison-based function in the retrieval algorithm so that the cases are retrieved in the decreasing order of expected losses. 


\section{Revise and Retain processes}

After the most similar cases are retrieved the user has to select the appropriate preventive or interceptive mechanism (as applicable) based on the current case. With more and more cases in the case base, the case base would be bulky and it would be difficult to select the best case for the present problem. At this point of time system needs an adaptation process. Based on the project features and other relevant user inputs, the risk preventive and interceptive strategies are adapted to the present problem. Rule-based case adaptation is widely used and is suitable for our problem. Rules are defined which restrict the application of suggested risk management strategies based on certain constraints. See Fig. 7 for an example.

Subsequent to a risk event if a successful risk management mechanism is identified, the experience should be retained in the case base as a new case. At this point in time the managers should also identify possible interceptive risk mechanisms which can be used to prevent the occurrence of the risk event. New cases should be retained with the approach suggested in fig. 5 .

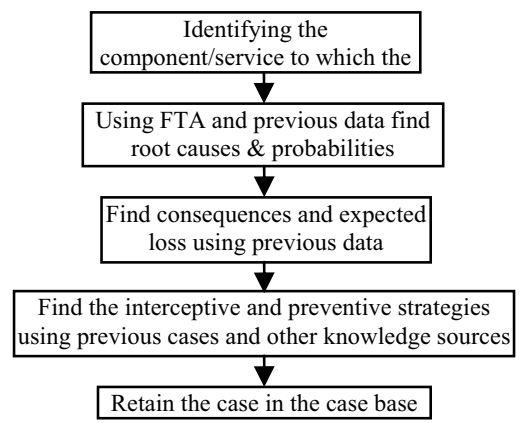

Fig. 5. Proposed approach for retaining a new case

\section{A SAMPLE CASE}

The case study of $\$ 100$ Million Durand Centre shopping mall (constructed on an existing site in southwest London, UK during early 1990's) construction considered here is described in detail in [12] and the reader is advised to refer to it.

The general contractor Stone Builders held contracts with various subcontractors. Standard penalty clauses for liquidated damages were in place. The two main subcontractors were Seaview Steelwork, who was responsible for off-site steel fabrication and on-site steel erection, and Boulder, who was responsible for concrete construction. Steel erection was on the critical path and Boulder's job was to follow the steel erection process of Seaview. After the concrete construction was over other subcontractors were to perform fire protection, blockwork, screed, cladding, and inverted roofing. The construction site was divided in six areas and Seaview was to follow the onsite steel erection sequence of areas $1>2 / 3>6>4 / 5$.

A delay in steel fabrication resulted a delay of six weeks in steel erection on-site. The delay was not anticipated and didn't become apparent until it occurred on-site. This case is a classic example of how supply chain risks affect a construction project. The company incurred an additional acceleration cost of $£ 231,000$ because of these risk events.

As steel erection was on critical path, a delay of six weeks could have been very costly. As per the contract, a six weeks project delay would have cost $£ 300,000$ with the liquidated damages of $£ 50,000$ per week. There could have been an extra cost of the allowance for claims from subcontractors for alterations in schedule also.

Stone decided not to let the delay propagate throughout the project, and spent $£ 231,000$ extra to pay the subcontractors for the acceleration of the project after the negotiations and discussions. Price paid to each subcontractor for acceleration is given in Table $\mathrm{V}$. It is mentioned in [12], that there could have been a better solution to the above mentioned problem, and the cost of project acceleration could have been lowered.

TABLE V

PRICE OF ACCELERATION PAID TO SUBCONTRATORS

\begin{tabular}{|l|l|}
\hline Subcontractor & Price to accelerate the program (in £) \\
\hline Floor slabs & 146,000 \\
\hline Fire protection & 34,800 \\
\hline Blockwork & 19,500 \\
\hline Screed & 0 \\
\hline Cladding & 0 \\
\hline Inverted roofing & 30,700 \\
\hline
\end{tabular}

After the delay was reported, the project management team of Stone Builders took an action based on the available information and experience of the team members. The knowledge available with this team was limited; hence the number of feasible solutions that could have been thought of by the team was limited as well.

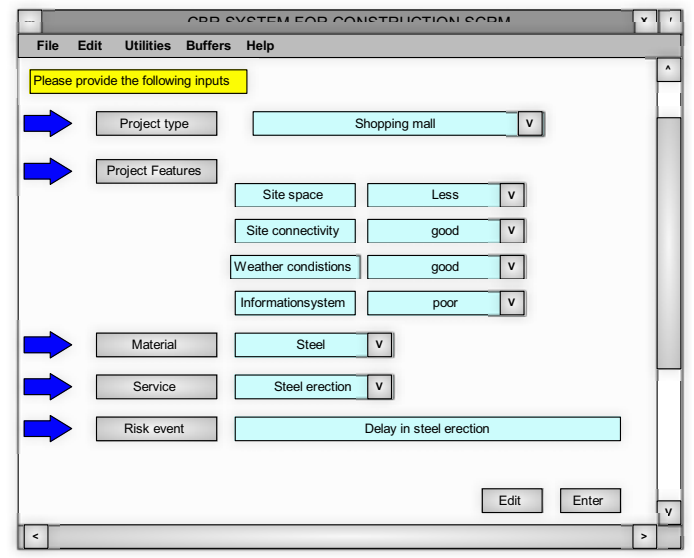

Fig. 6. User-system interface of CBR-DSS

A CBR-DSS which contains past similar cases of delay in steel erection could have helped managers find the various successful alternative actions that had been taken in the past and then the managers could have decided on the best 
possible solution to contain the loss due to delay. A sample of user-system interface screen of CBR-DSS is shown in Fig. 6. The figure shows only a few features in brief.

Sequential steps of user-system interface for the considered case have been presented in Fig. 7 .

\begin{tabular}{|c|c|c|}
\hline \multicolumn{3}{|c|}{ 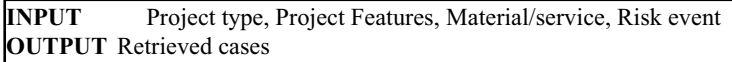 } \\
\hline \multirow[t]{5}{*}{ INPUT } & Adaptation rules & \\
\hline & 1. & Screed acceleration price $=0$ \\
\hline & & Cladding Acceleration price $=0$ \\
\hline & 3. & $\begin{array}{l}\text { Concrete construction acceleration price }= \\
£ 146,000\end{array}$ \\
\hline & 4. & No acceleration possible in steel erection \\
\hline OUTPUT & Adapted cases & \\
\hline \multicolumn{3}{|c|}{ User analysis of suggested cases } \\
\hline INPUT & Show in increasin & ng order of cost of solutions \\
\hline \multicolumn{3}{|c|}{ OUTPUT Case display in increasing order of cost of solutions } \\
\hline INPUT & Selection of lowe & est cost solutions and feasibility study \\
\hline
\end{tabular}

Fig. 7. Sequential steps of user-system interface during decision making

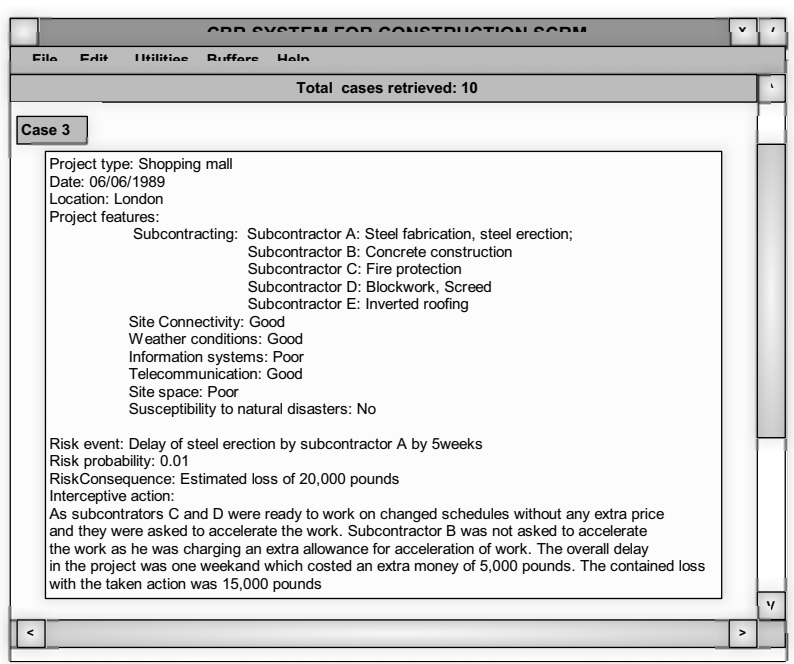

Fig. 8. A sample retrieved case providing feasible solution

Fig. 8 shows a sample retrieved case providing a feasible case.

\section{CONCLUSION}

We suggested an IT-enabled solution to the risk management problem in construction supply chains. The paper discussed the framework of an integrated DSS based on CBR, which can be used in preventive as well as interceptive risk management. As the DSS can be used flexibly for various different projects, it ensures the return on investments. For the firms who undertake projects in a particular segment, this CBR system would bring enormous savings. While the framework of CBR system is discussed in detail, preparation for such a system using risk analysis tools is also illustrated. Finally, using a case, we illustrated the input-output sequence of user-system interface and a sample retrieved case of the case-base. This case explains how the proposed CBR system can be used in practice.

\section{REFERENCES}

[1] A. Aamodt and E. Plaza, "Case-based reasoning: Foundational issues, methodological variations, and system approaches," Artificial Intelligence Communications, IOS Press, vol. 7(1), pp. 39-59, 1994.

[2] J. F. Al-Bahar and K. C. Crandall, "Systematic risk management approach for construction projects," Journal of Construction Engineering and Management, vol. 116 (3), pp. 533-546, Sept. 1990.

[3] D. Baloi and A. D. F. Price, "Modeling global risk factors affecting construction cost performance," International Journal of Project Management, vol. 21(4), pp. 261-269, May 2003.

[4] G. Briscoe, A. R. J. Dainty, and S. Millett, "Construction supply chain partnerships: skills knowledge and attitudinal requirements," European Journal of Purchasing and Supply Management, vol. 7 (4), pp. 243-255, Dec. 2001.

[5] A. R. J. Dainty, S. J. Millett, and G. H. Briscoe, "New Perspectives On Construction Supply Chain Integration," Supply Chain Management: An international Journal, vol. 6 (4), pp. 163-173, 2001.

[6] Ericsson, H. M. , "Managing construction supply chain by simulation," working paper, Helsinki University of Technology, Finland, 1999. Available: http://itc.scix.net/data/works/att/ecce-20018.content.pdf

[7] S. S. Hwang, T. Shin, and I Han, "CRAS-CBR: internal control risk assessment system using Case-Based Reasoning," Expert Systems, vol. 21 (1), pp. 22-33, Feb. 2003.

[8] C. Jung, I. Han, and B. Suh, "Risk analysis for electronic commerce using case-based reasoning," International Journal of Intelligent Systems in Accounting, Finance and Management, vol. 8, pp. 61-74, 1999.

[9] J. L. Kolodner, "Case-Based Reasoning," book, publisher: Morgan Kaufmann, Palo Alto, CA, 1993.

[10] N. D. Long, S. Ogunlana, T. Quang and K. C. Lam, "Large construction projects in developing countries: a case study from Vietnam," International Journal of Project Management, vol. 22 ( 7), pp. 553-561, Oct. 2004.

[11] B. Mulholland and J. Christian, "Risk assessment in construction schedules," Journal of Construction Engineering and Management, $A S C E$, vol. 125 (1), pp. 8-15, 1999.

[12] W. O'Brien, M. Fischer, and B. Akinci, "Importance of Site conditions and capacity allocation for construction cost and performance: A case study," in Tucker, S.N. (Ed.), Proceedings of the Fifth Annual Conference of the International Group for Lean Construction, Griffith University, Queensland, Australia. Available: http://www.iglc.net/conferences/1997/papers/OBRIEN.pdf

[13] W. J. O'Brien, “Construction supply chain management: a vision for advanced co-ordination, costing and control," Proceedings of the Berkeley-Stanford Construction Engineering and Management, Workshop: Defining a Research Agenda for AEC Process/Product Development in 2000 and Beyond, University of California, Berkeley, CA.

[14] W. O' Brien, "Enabling Technologies for Project Supply Chain Collaboration," NSF/ICIS Infrastructure and Information Technology Workshop, Arlington VA, 2001.

[15] J. H. M. Tah and V. Carr, "A proposal for construction project risk assessment using fuzzy logic," Construction Management \& Economics, vol. 18, pp. 491-500, 2000.

[16] J. H. M. Tah and V. Carr, "Towards a framework for project risk knowledge management in the construction supply chain," Advances in Engineering Software, vol. 32 (10), pp. 835-846, Oct. 2001.

[17] J. Taylor and H. Bjornsson, "Construction supply chain improvements through internet pooled procurement," Proceedings of IGLC-7, Berkeley, CA, 207-217, July 1999.

[18] A. Wong and P. Fung, "Total quality management in the construction industry in Hong Kong: A supply chain management perspective," Total Quality Management, vol. 10(2), pp. 199-208, 1999.

[19] J. Yan, P. E. Chaudhry, and S. S. Chaudhri, "A model of a decision support system based on Case-Based Reasoning for third party logistics evaluation," Expert Systems, vol. 20 (4), pp. 196-207, Sept 2003.

[20] S. D. Zoysa, Y. Wand, and A.D. Russel, "Use of IT in managing environmental risks in construction projects," ASCE conference proceedings, 2005. 